\title{
Chemical analysis of surgical smoke by infrared laser spectroscopy
}

\section{Journal Article}

\section{Author(s):}

Gianella, Michele; Sigrist, Markus W.

Publication date:

2012-11

Permanent link:

https://doi.org/10.3929/ethz-b-000059921

Rights / license:

In Copyright - Non-Commercial Use Permitted

Originally published in:

Applied Physics B 109(3), https://doi.org/10.1007/s00340-012-4920-1 


\title{
Chemical analysis of surgical smoke by infrared laser spectroscopy
}

\author{
Michele Gianella • Markus W. Sigrist
}

Received: 7 November 2011 / Revised version: 4 January 2012 / Published online: 2 March 2012

(C) Springer-Verlag 2012

\begin{abstract}
The chemical composition of surgical smoke, a gaseous by-product of some surgical devices-lasers, drills, vessel sealing devices - is of great interest due to the many toxic components that have been found to date. For the first time, surgical smoke samples collected during routine keyhole surgery were analyzed with infrared laser spectroscopy. Traces (ppm range) of methane, ethane, ethylene, carbon monoxide and sevoflurane were detected in the samples which consisted mostly of carbon dioxide and water vapor. Except for the anaesthetic sevoflurane, none of the compounds were present at dangerous concentrations. Negative effects on the health of operation room personnel can be excluded for many toxic compounds found in earlier studies, since their concentrations are below recommended exposure limits.
\end{abstract}

\section{Introduction}

The combustion and pyrolysis of biological tissue with heatgenerating surgical equipment-lasers, ultrasonic scalpels, high-frequency electroknives and high-speed drills and saws-produces an unwanted by-product called surgical smoke [1]. Surgical smoke has been shown to contain hundreds of chemical species, many of which are toxic or carcinogenic [1-15]. Moreover, surgical smoke is a viable transport mechanism for viruses [16-20], blood- and cellcontaining aerosols [20-22] and tissue fragments [23]. Although reports of infections transmitted via surgical smoke

M. Gianella · M.W. Sigrist $(\bowtie)$

Institute for Quantum Electronics, Laser Spectroscopy and

Sensing Lab, ETH Zurich, Schafmattstr. 16, 8093 Zurich,

Switzerland

e-mail: sigristm@phys.ethz.ch are rare $[17,18]$, the risk is not zero. Due to its potential toxicity to both operation room (OR) personnel and patients, knowledge about the chemical, biological and particulate composition of surgical smoke is of great interest. Recent studies of surgical smoke gathered in vivo relied on selected ion flow tube-mass spectrometry (SIFT-MS) [24] and gas chromatography-mass spectrometry (GC-MS) [2527]. These techniques are very sensitive and selective, but obtaining the concentration values necessary for risk assessment requires tedious calibrations. The detected compounds were mainly aromatic hydrocarbons, alkenes, alkanes, aldehydes and ketones; a selection thereof is given in Table 1. In particular, benzene and formaldehyde, two known carcinogens [28, 29], have been detected in surgical smoke at concentrations in the parts-per-billion (ppb) range [25].

Infrared laser spectroscopy, which probes the rovibrational structure of molecules, is a popular technique for the detection and quantification of trace amounts of molecular species. Its advantages include high sensitivity, selectivity, dynamical range and fast time response [30-39]. Although some applications profit from sample pretreatment (e.g. removal of water and carbon dioxide, preconcentration with cryo or thermal desorption traps), these steps are usually not necessary. Furthermore, concentrations can easily be computed given the measured transmittance or absorbance values and absorption cross sections. In this article we present a study of the chemical composition of surgical smoke obtained during routine colorectal keyhole (laparoscopic) surgery at the University Hospital Zurich (USZ). In contrast to open surgery, where surgical smoke is produced in an oxygen-nitrogen atmosphere, in laparoscopy the tissue pyrolysis takes place in a carbon dioxide atmosphere. Moreover, toxic compounds are not released into the atmosphere, but remain trapped within the abdominal cavity of the patient, from where they can be absorbed into the blood circulation. 
Table 1 Selection of chemical compounds detected in surgical smoke

\begin{tabular}{|c|c|c|c|c|c|}
\hline Name & CAS no. & Refs. & Name & CAS no. & Refs. \\
\hline Toluene & $108-88-3$ & {$[1-14,25,26,80]$} & Pentadecane & $629-62-9$ & {$[6,26]$} \\
\hline Ethylbenzene & $100-41-4$ & {$[1-12,14,25,26]$} & Tetradecane & $629-59-4$ & {$[2,26]$} \\
\hline Styrene & $100-42-5$ & {$[1,5-8,10-14,25]$} & Decane & $124-18-5$ & {$[2,26]$} \\
\hline Benzene & $71-43-2$ & {$[1,6-9,12-14,25]$} & Formaldehyde & $50-00-0$ & {$[1,25]$} \\
\hline Acrylonitrile & $107-13-1$ & {$[1,4,5,8,13,25,27]$} & 1-Butene & $106-98-9$ & {$[1,25]$} \\
\hline 1-Undecene & $821-95-4$ & {$[1-3,6,7,26]$} & Acetone & $67-64-1$ & {$[7,25]$} \\
\hline 1-Decene & $872-05-9$ & {$[1,3,6,7,26,80]$} & 1-Pentene & $109-67-1$ & {$[25,27]$} \\
\hline p-Xylene & $106-42-3$ & {$[2,6,7,25,26]$} & Heptanal & $111-71-7$ & {$[26]$} \\
\hline m-Xylene & $108-38-3$ & {$[2,6,7,25,26]$} & Nonanal & $124-19-6$ & [26] \\
\hline Furfural & 98-01-1 & {$[1-3,7,80]$} & Cyclohexanone & $108-94-1$ & {$[26]$} \\
\hline Propanenitrile & $107-12-0$ & {$[4,5,13,80]$} & Perchloroethylene & $127-18-4$ & {$[26]$} \\
\hline Hydrogen cyanide & $74-90-8$ & {$[1,12,24,81]$} & Tridecane & $629-50-5$ & {$[26]$} \\
\hline Propylbenzene & $103-65-1$ & {$[2,6,7,26]$} & Ammonia & $7664-41-7$ & {$[80]$} \\
\hline Isobutene & $115-11-7$ & {$[1,13,27,80]$} & 1-Hexene & $592-41-6$ & {$[25]$} \\
\hline 1-Heptene & $592-76-7$ & {$[6,7,25,80]$} & Isooctane & $540-84-1$ & {$[25]$} \\
\hline 1,3-Butadiene & $106-99-0$ & {$[1,24,27,80]$} & Propadiene & $463-49-0$ & [27] \\
\hline Carbon monoxide & $630-08-0$ & {$[1,12,25,81]$} & Vinylacetylene & $689-97-4$ & {$[27]$} \\
\hline Propene & $115-07-1$ & {$[1,13,25,27]$} & Mercaptomethane & 74-93-1 & [27] \\
\hline Ethylene & $74-85-1$ & {$[1,13,80]$} & Ethylacetylene & $107-00-6$ & [27] \\
\hline Methylthiocyanate & $556-64-9$ & {$[6,7,80]$} & Diacetylene & $460-12-8$ & [27] \\
\hline 1-Dodecene & $112-41-4$ & {$[6,7,26]$} & Ethanol & $64-17-5$ & {$[27]$} \\
\hline 1-Tetradecene & $1120-36-1$ & {$[6,7,26]$} & Piperylene & $540-60-9$ & {$[27]$} \\
\hline Acetylene & $74-86-2$ & {$[1,13,24]$} & Propenylacetylene & $2206-23-7$ & [27] \\
\hline o-Xylene & $95-47-6$ & {$[6,25,26]$} & 1,4-Pentadiene & $591-93-5$ & [27] \\
\hline 3-Methylstyrene & $100-80-1$ & {$[2,80]$} & Cyclopentadiene & $542-92-7$ & [27] \\
\hline 1-Dodecane & $112-40-3$ & {$[2,26]$} & Butyrolactone & $96-48-0$ & [27] \\
\hline 1-Undecane & $1120-21-4$ & {$[2,26]$} & & & \\
\hline
\end{tabular}

\section{Experimental}

Two infrared laser spectrometers and a Fourier-transform infrared (FTIR) spectrometer were used to measure the absorption spectra of surgical smoke.

\subsection{Mid-IR (MIR) difference frequency generation (DFG) laser spectrometer}

Difference-frequency generation (DFG) [40] was employed to produce laser radiation near $3000 \mathrm{~cm}^{-1}$, the fundamental $\mathrm{C}-\mathrm{H}$ stretch vibration region. The experimental setup is shown in Fig. 1 and is described in detail elsewhere [41, 42]. Briefly, a tunable continuous wave (cw) external cavity diode laser (ECDL) emitting at $1520-1600 \mathrm{~nm}$ (Santec Corp., model TSL-210, Japan) and a Q-switched Nd:YAG laser (InnoLight GmbH, model M800, Germany) emitting 5-ns pulses with $5-10 \mathrm{kHz}$ repetition rate at a wavelength of $1064.55 \mathrm{~nm}$ are mixed in a 5-cm-long periodically poled lithium niobate (PPLN) crystal with eight different poling periods. The output power of the ECDL is about $5 \mathrm{~mW}$, whereas the average power of the Nd:YAG laser is around $150-300 \mathrm{~mW}$ (peak power: $5 \mathrm{~kW}$ ). The generated idler beam is pulsed with about $150 \mu \mathrm{W}$ of average power, a line width of $150 \mathrm{MHz}$ and is tunable between 2815 and $3144 \mathrm{~cm}^{-1}$ using two different poling periods of the PPLN crystal. Part of the idler beam is directed to a thermoelectrically cooled $(\mathrm{HgCdZn}) \mathrm{Te}$ detector (Vigo Systems SA, model PDI-2TE-4/VPDC-0.1i) for power normalization. A Herriott-type home-built 35-m multipass cell (MPC) [43] holds the sample under investigation. The idler beam is guided into and out of the multipass cell through the same window. A second identical detector measures the power transmitted through the sample in the multipass cell.

A measurement of the 'empty' (evacuated or filled with some non-absorbing gas such as nitrogen or a rare gas) multipass cell provides the baseline of the system. This baseline contains fringe patterns that cannot be accurately described over the entire tuning range of the spectrometer $\left(329 \mathrm{~cm}^{-1}\right)$ with simple functions (polynomials, sine/cosine, ...). Furthermore, the fringe patterns are not stationary over more 


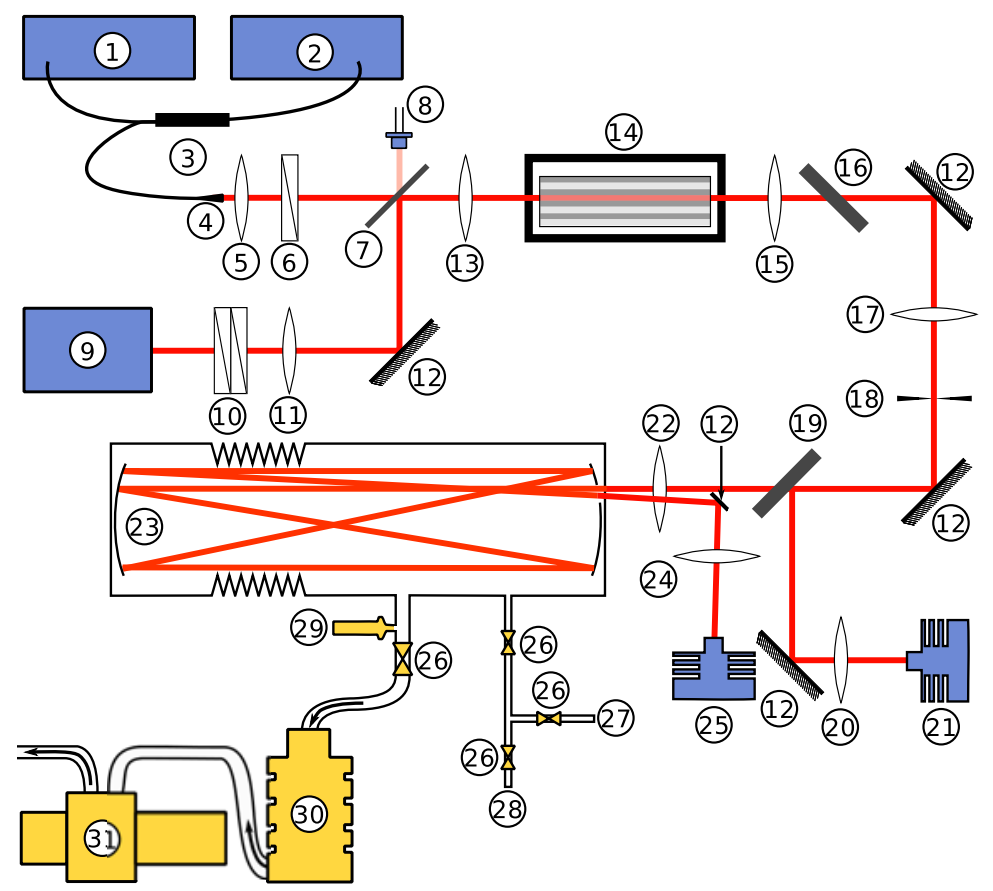

Fig. 1 Schematic drawing of the mid-IR difference-frequencygeneration-based laser spectrometer: (1) cw external cavity diode laser; (2) wavemeter for ECDL; (3) polarization-maintaining (PM) fiber with fiber coupler; (4) fiber output coupler; (5) $f=400 \mathrm{~mm}$ lens; (6) halfwave plate; (7) dichroic mirror; (8) Si photodiode; (9) Q-switched Nd:YAG laser; (10) half and quarter-wave plates; (11) $f=200 \mathrm{~mm}$ lens; (12) mirrors; (13) $f=75 \mathrm{~mm}$ lens; (14) crystal oven with periodically poled lithium niobate (PPLN) crystal; (15) $f=99 \mathrm{~mm} \mathrm{CaF}_{2}$

than a few hours. Hence, every sample measurement must be followed (or preceded) by a baseline measurement. The ratio of the two measurements then provides the sample transmittance $\mathscr{T}$ :

$\mathscr{T}=\frac{Q}{B}$,

where $Q$ is the detector signal ratio of the sample measurement,

$Q \equiv \frac{\text { transmitted power }}{\text { reference power }}$,

and $B$ is the detector signal ratio of the corresponding baseline measurement.

Tuning of the DFG source occurs by simultaneously changing the PPLN crystal temperature and the signal laser wavelength [41]. This technique improves the reproducibility of the measurements by forcing the PPLN crystal temperature and laser wavelength to follow the same predefined timetable during each measurement, and by keeping the scan duration as short as possible. For example, a wavelength scan from 2900 to $3144 \mathrm{~cm}^{-1}$ requires tuning of the signal laser wavelength from 1540 to $1600 \mathrm{~nm}$ and increasing the PPLN temperature from 40 to $173^{\circ} \mathrm{C}$. Due to the large lens; (16) germanium filter; (17) $f=379 \mathrm{~mm} \mathrm{CaF}_{2}$ lens; (18) variablediameter aperture; (19) $\mathrm{CaF}_{2}$ beam splitter; (20) $f=200 \mathrm{~mm} \mathrm{CaF} 2$ lens; (21) reference detector; (22) $f=300 \mathrm{~mm} \mathrm{CaF}_{2}$ lens; (23) multipass cell (MPC, max. path length $35 \mathrm{~m}$ ); (24) $f=100 \mathrm{~mm} \mathrm{CaF}_{2}$ lens; (25) transmission detector; (26) valves; (27) connection to gas bottles (nitrogen, carbon dioxide); (28) connection to sample bags; (29) pressure gauge; (30) turbopump; (31) rotary pump

temperature change, this procedure cannot be made arbitrarily fast. In the example above, the measurement takes just over an hour if the PPLN crystal temperature is increased at $2^{\circ} \mathrm{C} / \mathrm{min}$. The second measurement can only be started once the initial temperature of the PPLN crystal has been re-established, which takes 30 to $45 \mathrm{~min}$. Hence, about $1.5 \mathrm{~h}$ elapse between the starts of the first and second measurements.

The detector signal ratio $Q$ of the MPC filled with argon (purity 4.8) at a fixed wavelength and at a pressure of 964 mbar was measured over $7 \mathrm{~h}$. The Allan plot [44] for this data is given in Fig. 2. It is apparent that averaging for longer than about $0.2 \mathrm{~s}$ only slightly decreases the (relative) Allan deviation $\sigma_{Q}^{(A)} / Q$ from its initial value of $0.05 \%$. This value would imply a sensitivity of $\alpha_{\min }=$ $1.4 \times 10^{-7} \mathrm{~cm}^{-1}$ (for $35 \mathrm{~m}$ path length). Better sensitivities down to $4 \times 10^{-8} \mathrm{~cm}^{-1}$ can be achieved at wavelengths where more idler power is available. However, as a second measurement (the baseline $B$, taken $1.5 \mathrm{~h}$ later) is required to obtain transmittance values (see (1)), any drifts occurring during this time will introduce an error in the transmittance. The sensitivity of the system can be estimated by comparing two measurements $A_{1}$ and $A_{2}$, both with averaging time $\tau$, taken $1.5 \mathrm{~h}$ apart at the same wavelength. The square root of 


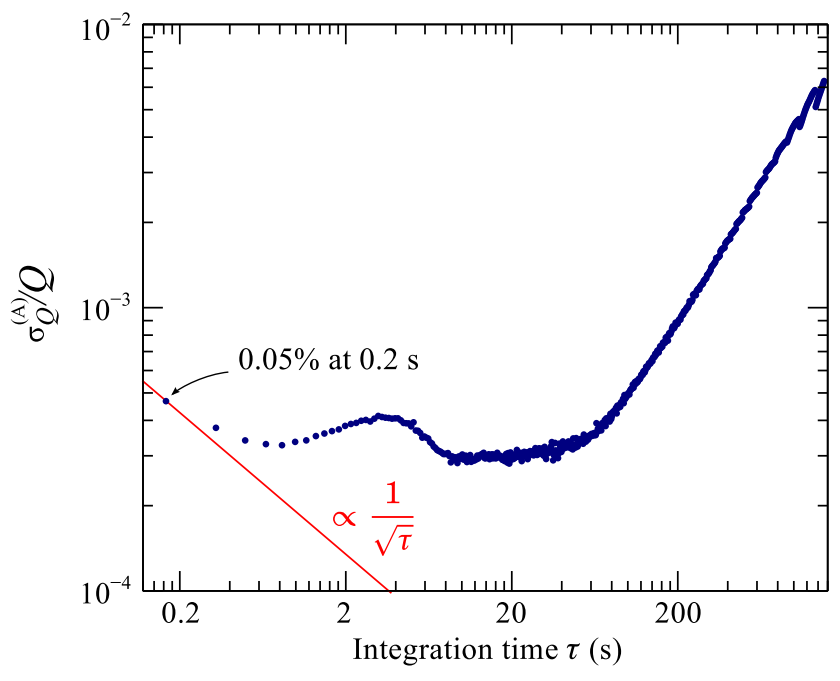

Fig. 2 Relative Allan deviation plot for the detector signal ratio (see (2)) measured at a constant wavelength and PPLN crystal temperature over $7 \mathrm{~h}$

the general two-sample variance $\sigma_{Q}^{2}(N, T, \tau)[44,45]$ with $N=2, T=1.5 \mathrm{~h}$ and $\tau=0.2 \mathrm{~s}$,

$\sigma_{Q}^{2} \equiv \frac{1}{2}\left(A_{1}-A_{2}\right)^{2}$

is an estimator for the sensitivity of the system. Notice that this is the same expression as for the Allan variance (Eq. (5) in [44]), with the only difference that here $A_{1}$ and $A_{2}$ are not measured immediately after one another. The uncertainty in the transmittance can then be estimated from (1) as

$\frac{\sigma_{\mathscr{T}}}{\mathscr{T}}=\sqrt{\left(\frac{\sigma_{Q}}{Q}\right)^{2}+\left(\frac{\sigma_{B}}{B}\right)^{2}} \approx \sqrt{2} \frac{\sigma_{Q}}{Q}=0.7 \%$,

where $\sigma_{Q} / Q \equiv \sqrt{\sigma_{Q}^{2}(N=2, T=1.5 \mathrm{~h}, \tau=0.2 \mathrm{~s}) / Q^{2}}=$ $0.5 \%$, corresponding to a smallest measurable absorption coefficient of $\alpha_{\min }=9 \times 10^{-7} \mathrm{~cm}^{-1}$. In (4), it was assumed that $Q \approx B$ and $\sigma_{Q} \approx \sigma_{B}$. In Fig. 3, three consecutive baseline measurements were divided by a previously taken measurement. The expected value for the transmittance $\mathscr{T}$ is 1 . Root-mean-square deviations range from $0.4 \%$ to $0.7 \%$, in good agreement with (4). The key parameters of the spectrometer are summarized in Table 2.

\subsection{Near-IR (NIR) spectrometer with two distributed feedback diode lasers}

Two distributed feedback (DFB) laser diodes emitting at $2323.6 \mathrm{~nm}\left(4303.6 \mathrm{~cm}^{-1}\right)$ and $2433.1 \mathrm{~nm}\left(4110 \mathrm{~cm}^{-1}\right)$ were used to probe the $R(12)$ absorption line of the $v=2 \leftarrow 0$ overtone transition of carbon monoxide ( $\mathrm{CO}$, line strength $2.28 \times 10^{-21} \mathrm{~cm} /$ molecule) and the $R(3)$ absorption line of the $v=1 \leftarrow 0$ fundamental transition of hydrogen fluoride (HF, line strength $1.59 \times 10^{-18} \mathrm{~cm} /$ molecule), respectively. Both diodes were manufactured by Nanoplus
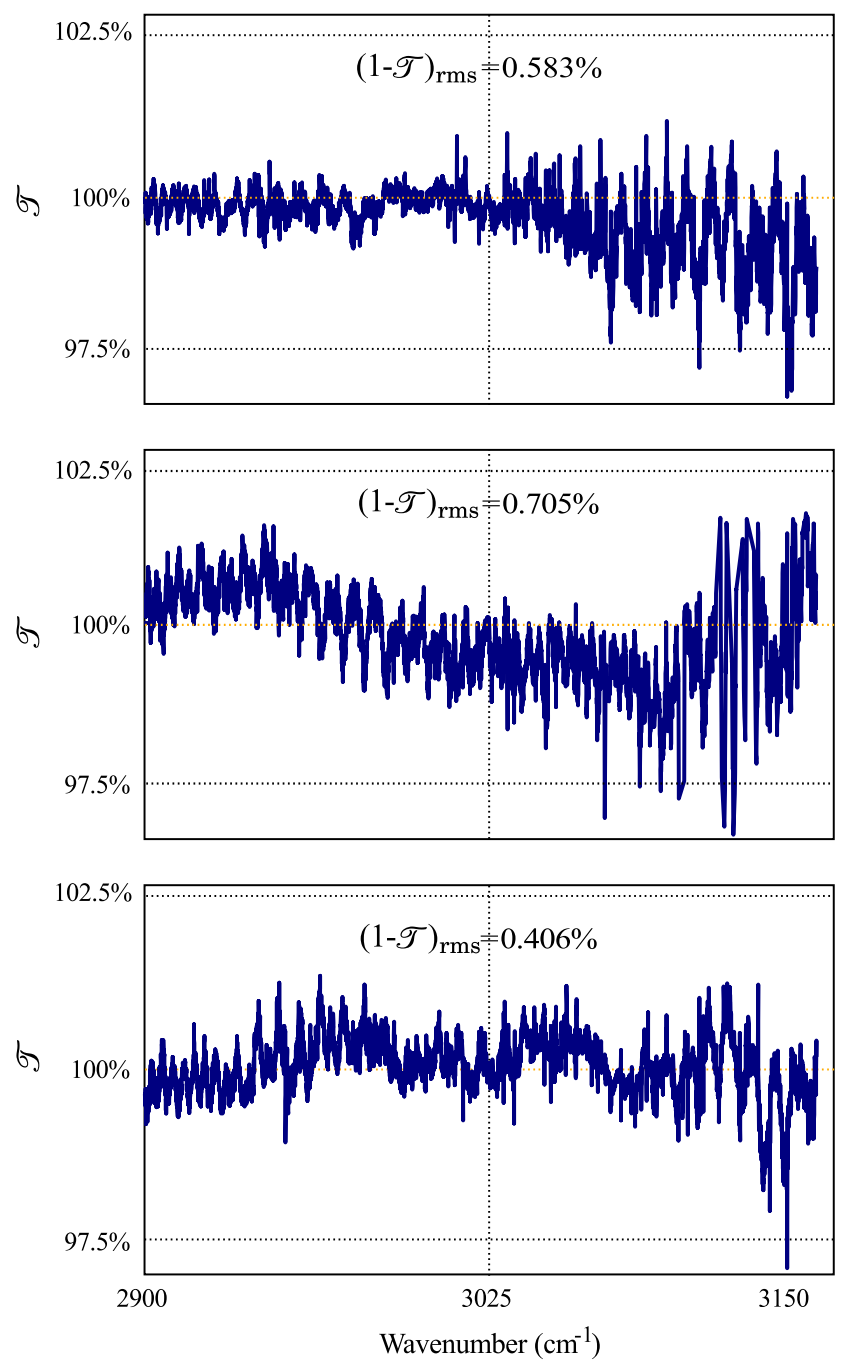

Fig. 3 Three consecutive baseline measurements divided by a fourth measurement taken first (not shown). The expected value for the transmittance $\mathscr{T}$ is 1 . The root-mean-square (rms) of the deviation is given in the figure

GmbH, Germany. These wavelengths are not accessible with our MIR DFG spectrometer, nor are there any overtone bands of $\mathrm{HF}$ and $\mathrm{CO}$ in its tuning range. The spectrometer is shown in Fig. 4. Each diode is housed in a thermoelectrically cooled laser diode mount (Thorlabs, model TCLDM9, Germany). The beam is collimated by a $f=12.7 \mathrm{~mm} \mathrm{CaF}_{2}$ lens. Two silver-coated mirrors guide the beam into the multipass cell (MPC, New Focus, model 5611, USA) through a $\mathrm{CaF}_{2}$ window. The total absorption path length was determined to be $8 \mathrm{~m}$, corresponding to 40 passes. The transmitted beam is focused by an off-axis parabolic mirror $(f=100 \mathrm{~mm})$ onto a thermoelectrically cooled detector (Vigo Systems SA, model PDI2TE-4/VPDC-0.1i). The peak responsivity of this detector is at $4 \mu \mathrm{m}$, but with the available power $(2-3 \mathrm{~mW})$ the signal-to-noise ratio is more than adequate even at 2.3-2.4 $\mu \mathrm{m}$. For measurements based on the wavelength- 
modulation (WM) technique [30, 46-48], the ramp frequency was $3.3 \mathrm{~Hz}$ and the modulation frequency was $f_{\mathrm{m}}=$

Table 2 Key parameters of the mid-IR difference-frequencygeneration-based laser spectrometer

\begin{tabular}{ll}
\hline Property & Specification \\
\hline Tuning range $^{\mathrm{a}}$ & $2815-3144 \mathrm{~cm}^{-1}(3.18-3.55 \mu \mathrm{m})$ \\
Line width $^{-150 \mathrm{MHz}}$ \\
Tuning rate $^{\mathrm{b}}$ & $3.67 \mathrm{~cm}^{-1} / \mathrm{min}$ \\
Power & avg. $150 \mu \mathrm{W}$, peak $5 \mathrm{~W}$ \\
Absorption path length & $35 \mathrm{~m}$ \\
Sensitivity $\alpha_{\text {min }}$ & $9 \times 10^{-7} \mathrm{~cm}^{-1}$ \\
Sensitivity $^{\mathrm{c}} \alpha_{\text {min }}$ & $4 \times 10^{-8}-4 \times 10^{-7} \mathrm{~cm}^{-1}$ \\
\hline
\end{tabular}

${ }^{\text {a }}$ Requires two different PPLN crystal poling periods

${ }^{b}$ Heating the PPLN crystal at $2{ }^{\circ} \mathrm{C} / \mathrm{min}$

${ }^{\mathrm{c}}$ If a baseline measurement is not necessary, i.e. for measurements of isolated absorption lines; $0.2 \mathrm{~s}$ averaging time
$45 \mathrm{kHz}$. A lock-in amplifier (Stanford Research, model SR830, USA) was used for measurement of the secondharmonic amplitude (at $2 f_{\mathrm{m}}=90 \mathrm{kHz}$ ). For direct transmission measurements, the modulation was switched off and the ramp frequency was increased to about $1 \mathrm{kHz}$. Sweep integration $[49,50]$ was employed in order to suppress laser and detector $1 / f$-noise. The detector signal was oversampled at $100 \mathrm{MHz}$ with a 14-bit ADC card (Gage, model CS14100, USA) and then decimated to increase ADC resolution.

The key parameters of the spectrometer are given in Table 3. Interference fringes are suppressed by dithering the length of the multipass cell and the distance between the laser diode and the collimating lens. However, it is not possible to completely remove the fringes, and the effectiveness of the cancellation is not reproducible. The residual fringes after 1-min averaging limit the sensitivity to about $10^{-8} \mathrm{~cm}^{-1}$.

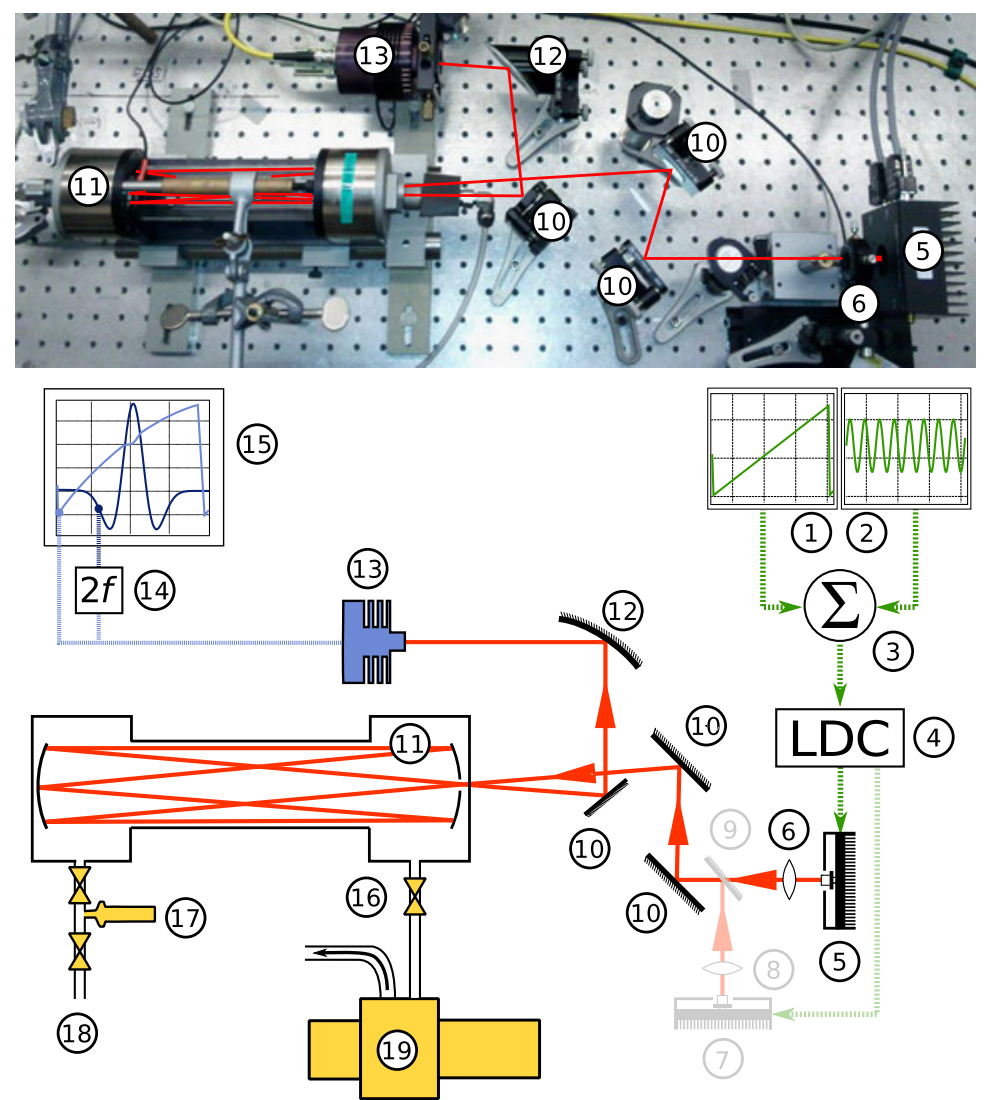

Fig. 4 Upper part: photograph of the NIR laser spectrometer, with beam path drawn in. Lower part: schematic drawing: (1) voltage ramp generator; (2) voltage sine generator; (3) adder; (4) laser diode current driver; (5) thermoelectrically (TE) cooled laser diode mount and DFB laser diode A $(\lambda=2433.1 \mathrm{~nm})$; (6) collimating $\mathrm{CaF}_{2} f=12.7 \mathrm{~mm}$ lens; (7) TE-cooled laser diode mount and DFB laser diode $\mathrm{B}(\lambda=$ $2323.6 \mathrm{~nm}$ ); (8) collimating $\mathrm{CaF}_{2} f=12.7 \mathrm{~mm}$ lens; (9) flipping mir- ror; (10) silver-coated mirror; (11) multipass gas cell (MPC) with $\mathrm{CaF}_{2}$ window; (12) off-axis parabolic silver-coated mirror $(f=10 \mathrm{~cm})$; (13) TE-cooled HgCdZnTe detector; (14) lock-in amplifier (secondharmonic detection); (15) oscilloscope or acquisition card; (16) valve; (17) pressure gauge; (18) inlet for gas samples; (19) rotary vacuum pump 
Table 3 Key parameters of the near-IR laser spectrometer

\begin{tabular}{lll}
\hline Property & Specification \\
\cline { 2 - 3 } & Diode A & Diode B \\
\hline Wavelength & $2433.1 \mathrm{~nm}$ & $2323.6 \mathrm{~nm}$ \\
Line width & $<3 \mathrm{MHz}$ & $<3 \mathrm{MHz}$ \\
Power & $2 \mathrm{~mW}$ & $3 \mathrm{~mW}$ \\
Absorption path length & $8.0 \mathrm{~m}$ & $8.0 \mathrm{~m}$ \\
Sensitivity $\alpha_{\text {min }}$ (noise-equivalent) & $8.5 \times 10^{-10} \mathrm{~cm}^{-1} \mathrm{~Hz}^{-1 / 2}$ & $8.5 \times 10^{-10} \mathrm{~cm}^{-1} \mathrm{~Hz}^{-1 / 2}$ \\
Sensitivity (actual) & $1 \times 10^{-8} \mathrm{~cm}^{-1}$ & $3.1 \times 10^{-8} \mathrm{~cm}^{-1}$ \\
Limit of detection (LOD) & $110 \mathrm{ppt} \mathrm{HF}$ & $250 \mathrm{ppb} \mathrm{CO}$
\end{tabular}

\subsubsection{Remark about absorption path length and number of passes in multipass cells (MPCs)}

The transmittance through a single-pass cell with length $\ell$ is given by Beer-Lambert's law:

$\mathscr{T}=\exp (-\alpha \ell)$

where $\alpha$ is the absorption coefficient. In a MPC, where the beam experiences $n$ reflections on mirrors of reflectivity $R$, the transmittance becomes

$\mathscr{T}_{n}(\alpha)=R^{n} \exp (-\alpha(n+1) \ell)$.

The most simple way to determine the absorption coefficient on the peak of an isolated absorption line is to take a measurement $s_{0}$ off the absorption line, and one measurement $s_{1}$ on the absorption line. Given the following expressions for $s_{0}$ and $s_{1}$,

$s_{0}=P_{0} \mathscr{T}_{n}(0)=P_{0} R^{n}$,

$s_{1}=P_{0} \mathscr{T}_{n}(\alpha)=P_{0} R^{n} \exp (-\alpha(n+1) \ell)$,

with $P_{0}$ the laser power incident on the MPC, the absorption coefficient $\alpha$ can be computed if $n, \ell$ and the ratio $s_{1} / s_{0}$ are known:

$\alpha=-\frac{1}{(n+1) \ell} \ln \left(\frac{s_{1}}{s_{0}}\right)$.

The sensitivity (and precision) of the system are determined by the standard deviation $\sigma_{\alpha}$ of $\alpha$ :

$\sigma_{\alpha}=\frac{\sqrt{2}}{(n+1) \ell} \frac{\sigma_{s}}{s}$,

where it was assumed that $s_{0}=s_{1}=s$ (zero absorption) and $\sigma_{s_{0}}=\sigma_{s_{1}} \equiv \sigma_{s}$ (same noise in both measurements). A simple model for $\sigma_{s}$ is

$\sigma_{s}=\sqrt{\sigma_{\mathrm{d}}^{2}+\sigma_{1}^{2}}=\sqrt{\sigma_{\mathrm{d}}^{2}+\left(P_{0} \kappa R^{n}\right)^{2}}$,

where $\sigma_{\mathrm{d}}$ is the noise-equivalent power of the detector (within a given detection bandwidth $b$ ) and $\sigma_{1}=P_{0} \kappa R^{n}$ is the absolute laser power noise (within the same detection

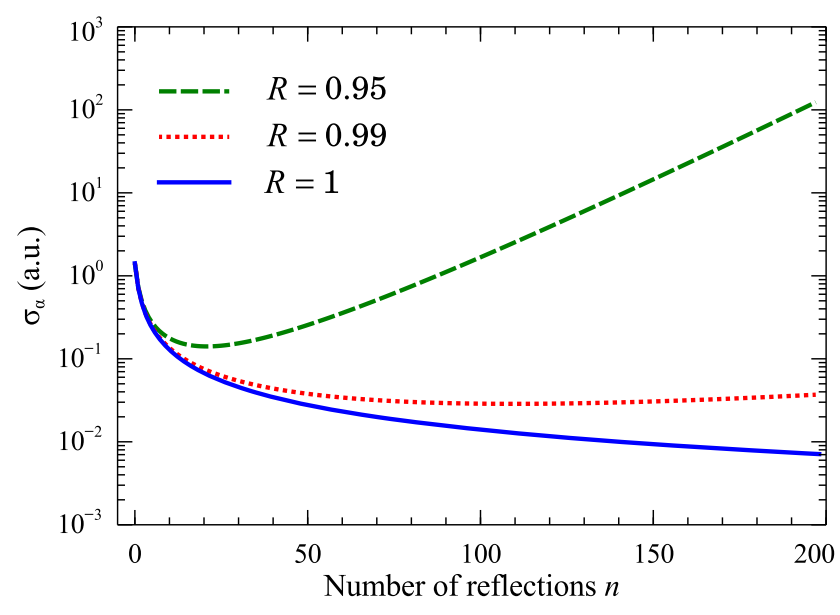

Fig. 5 Calculated standard deviation of the absorption coefficient $\alpha$ for ideal (reflectivity $R=1)$ and real $(R=0.99, R=0.95)$ mirrors versus number of reflections $n$ in a multipass cell, taking into account laser and detector noise. The minima are located at $n^{*} \approx \infty, 100,20$ for $R=1,0.99,0.95$, respectively

bandwidth $b$ ), with $\kappa$ the relative intensity noise (RIN). By inserting (10) into (9), we obtain

$\sigma_{\alpha}=\frac{\sqrt{2}}{(n+1) \ell} \sqrt{\frac{\eta^{2}}{R^{2 n}}+\kappa^{2}}$,

with $\eta \equiv \sigma_{\mathrm{d}} / P_{0}$. The minimum of $\sigma_{\alpha}$ can be computed by setting its derivative with respect to $n$ equal to zero.If $\kappa=0$, the expression becomes very simple: the minimum of $\sigma_{\alpha}$ is located at

$n^{*}=\frac{-1}{\ln R}-1$.

In Fig. 5, $\sigma_{\alpha}$ is plotted versus $n$ for the arbitrary choice of $\eta=\kappa \neq 0$ and three different mirror reflectivities. There is no significant difference if $\eta \neq \kappa$, as long as both are different from zero. Although the noise model (see (10)) is very simple and does not take into account, for example, diffraction losses, interference effects (fringes), and mechanical vibrations, it implies that with mirrors of relatively low reflectivity one should consider working with a lower number of passes (e.g. with $R=0.97 \rightarrow n^{*}=32$ ). 

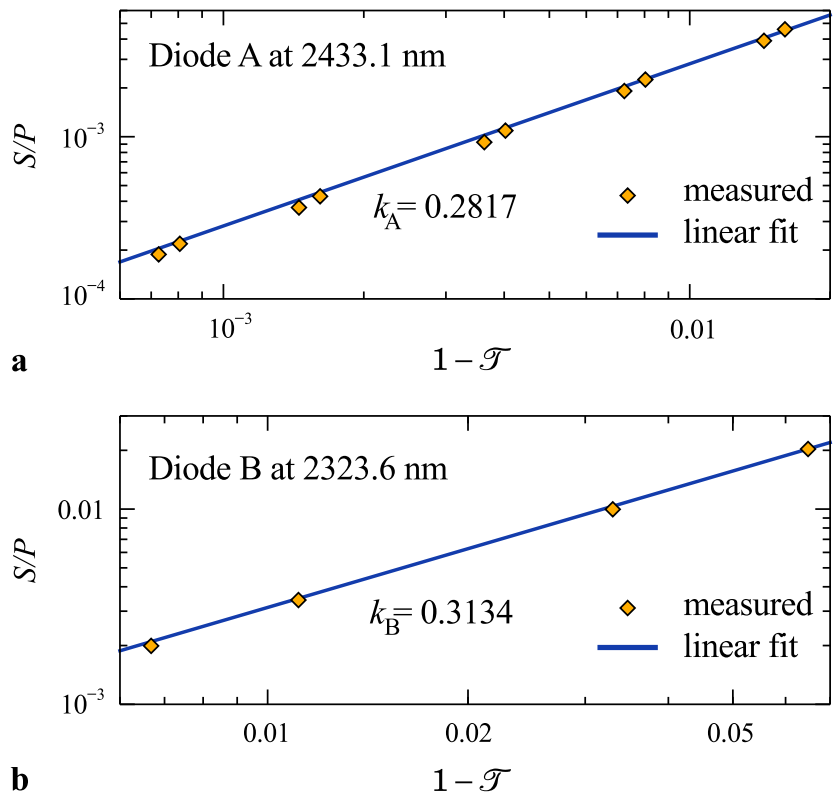

Fig. 6 Calibration of the near-IR spectrometer when used in wavelength-modulation (WM) mode. The power-normalized amplitude $(S / P)$ of the second harmonic measured at the center of the absorption line is plotted versus the absorption $1-\mathscr{T}$. The relationship is linear with the slopes $k_{\mathrm{A}}$ and $k_{\mathrm{B}}$

\subsubsection{Calibration of the NIR spectrometer}

To establish the total absorption path length inside the MPC, absorption lines of carbon monoxide (CO) and methane $\left(\mathrm{CH}_{4}\right)$ were measured at known concentrations in direct transmission mode, i.e. without wavelength modulation. The line parameters were taken from HITRAN [51] and the absorption path length $\mathscr{L}$ was used as a fit parameter. The total absorption path length was found to be $\mathscr{L}=8.0 \pm 0.1 \mathrm{~m}$.

When the spectrometer was used in direct transmission mode, no calibration was necessary. For the measurements carried out with wavelength modulation, the spectrometer was calibrated by measuring the power-normalized amplitude of the second harmonic at the center of the absorption line for different concentrations of carbon monoxide and methane. The results are shown in Fig. 6. The data points appear paired because two methane absorption lines with different line strengths were measured at each concentration. The relationship between the absorption $1-\mathscr{T}$ and the power-normalized amplitude $S / P$ is

$\frac{S}{P}=k(1-\mathscr{T})$,

with $k_{\mathrm{A}}=0.2817$ for the diode A emitting at $2433.1 \mathrm{~nm}$ and $k_{\mathrm{B}}=0.3134$ for the diode $\mathrm{B}$ emitting at $2323.6 \mathrm{~nm}$. These values can be used to calibrate the vertical axis in wavelength-modulation measurements (see Fig. 9, later).

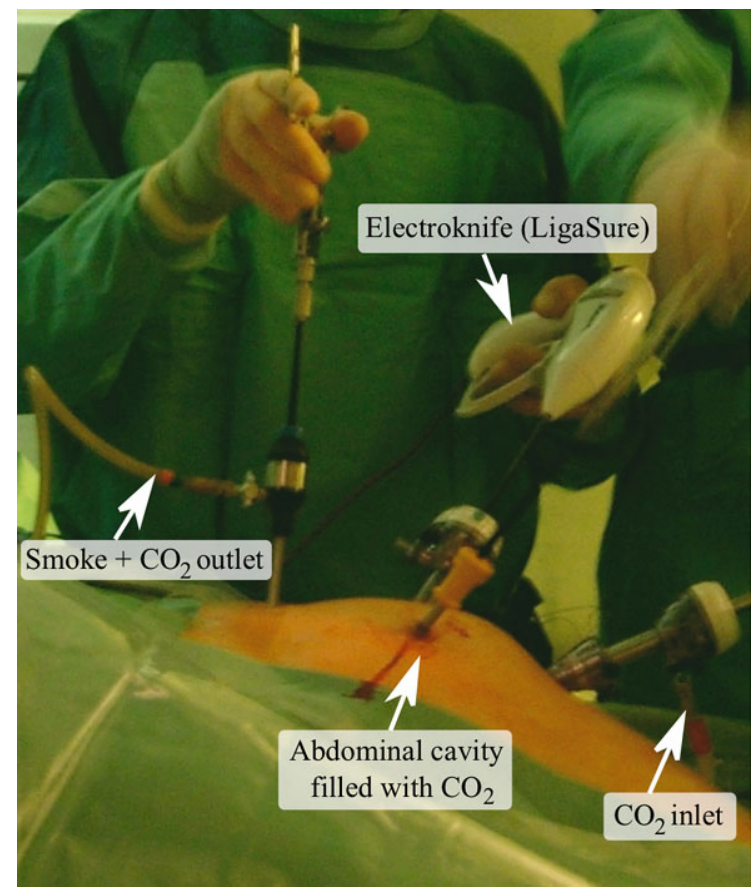

Fig. 7 Photograph taken at the University hospital Zurich (USZ) during keyhole surgery. The electroknife is a vessel sealing device which produces small amounts of (surgical) smoke

\subsection{Fourier-transform infrared (FTIR) spectrometer}

Two samples were measured with a commercial Fouriertransform infrared (FTIR) spectrometer (Bruker Optics, model IFS66v, USA) with a resolution of $0.125 \mathrm{~cm}^{-1}$ and 4-m absorption path length.

\subsection{Sample collection}

All the samples analyzed in this work originated from routine colorectal laparoscopic (keyhole) surgeries at the University Hospital Zurich (USZ). During the procedures, a high frequency vessel sealing device (ValleyLab, model LigaSure, USA) was employed (Fig. 7). A 3 L Tedlar® bag (CEL Scientific, USA) was connected to one of the trocars with a sterile gas tube. The abdominal cavity of the patient was filled with carbon dioxide (the abdominal cavity filled with a gas is called the pneumoperitoneum) with an overpressure of about 20 mbar. Whenever the vessel sealing device was active, the valve on the trocar was opened and the small overpressure of the pneumoperitoneum filled the sample bag. Several sample bags were filled during each operation and then transported to our laboratory for analysis. The list of measured samples is given in Table 4 . Of the $33 \mathrm{col}-$ lected samples, 29 were measured with the MIR DFG spectrometer, six with the NIR spectrometer and two with the FTIR spectrometer. 
Table 4 Overview of the samples collected at the University hospital Zurich. For each operation $(O p$. $) \mathrm{H} 01-\mathrm{H} 06$, several sample bags were filled $(\mathrm{a}, \mathrm{b}, \mathrm{c}, \ldots)$. The spectrometer they were measured with is indicated with a $\mathbf{\square}$ in the respective column
${ }^{a}$ Mid-IR DFG spectrometer

${ }^{b}$ Near-IR spectrometer (HF, CO)

\begin{tabular}{lllll}
\hline Op. Bag & Content & Measured with & \multirow{2}{*}{ Remarks } \\
\cline { 3 - 4 } & & &
\end{tabular}

\begin{tabular}{|c|c|c|c|c|c|}
\hline \multirow[t]{3}{*}{ H01 } & $\mathrm{a}$ & $\mathrm{CO}_{2}$ & $\mathbf{\square}$ & $\mathbf{\square}$ & Medical $\mathrm{CO}_{2}$ \\
\hline & $b-e$ & Smoke & $\mathbf{\square}$ & & \\
\hline & $\mathrm{f}$ & Smoke & $\mathbf{\square}$ & $\mathbf{\square}$ & \\
\hline $\mathrm{H} 02$ & $a-f$ & Smoke & $\mathbf{\square}$ & & \\
\hline \multirow[t]{2}{*}{$\mathrm{H} 03$} & $\mathrm{a}$ & $\mathrm{CO}_{2}$ & $\mathbf{\square}$ & & $\begin{array}{l}\text { Medical } \mathrm{CO}_{2} \text { flushed through } \\
\text { abdominal cavity of patient }\end{array}$ \\
\hline & $b-f$ & Smoke & $\mathbf{\square}$ & & \\
\hline $\mathrm{H} 04$ & $a-i$ & Smoke & $\square$ & & \\
\hline \multirow[t]{2}{*}{$\mathrm{H} 05$} & $a-b$ & Smoke & & $\mathbf{\square}$ & \\
\hline & $\mathrm{c}$ & Smoke & $\mathbf{\square}$ & $\mathbf{\square}$ & \\
\hline \multirow[t]{2}{*}{ H06 } & $\mathrm{a}$ & Smoke & $\mathbf{\square}$ & $\mathbf{\square}$ & \\
\hline & $b-c$ & Smoke & & 口 & \\
\hline
\end{tabular}

\section{Results}

The 'blank' samples H01a and H03a (Table 4) were measured with the MIR spectrometer to verify that there was no contamination of the medical $\mathrm{CO}_{2}$ gas and that the employed Tedlar® bags were suited for the task. In both samples only water vapor $(0.72-0.92 \%)$ was detected.

The spectra measured with the MIR DFG spectrometer were qualitatively similar for most of the 27 measured smoke samples. The spectra were analyzed with a specially developed algorithm [52] and a database of FTIR spectra [53]. A typical absorption spectrum measured at room temperature and ambient pressure is shown in Fig. 8. Several absorption lines appear throughout the measured spectral range. They belong to water vapor, methane, ethane and ethylene (Fig. 8b). The four broader absorption features are due to sevoflurane, a liquid volatile anaesthetic commonly used in surgery [54]. It is inhaled by the patient during the surgery at concentrations in the percent range, but it is unclear how it reaches the abdominal cavity. In an attempt to increase the overall sensitivity of the spectrometer, about $25 \mathrm{~L}$ of surgical smoke were pumped through a thermal desorption tube filled with $2.877 \mathrm{~g}$ of Carboxen 569 (Supelco, USA) and later desorbed at $270^{\circ} \mathrm{C}$ with $400 \mathrm{~mL} / \mathrm{min}$ nitrogen 5.0 in a total volume of $2 \mathrm{~L}$. We observed about $5 \mathrm{ppm}$ of formaldehyde, but separate measurements showed that formaldehyde is produced when sevoflurane is exposed to high temperatures. Moreover, the preconcentration $(25 \mathrm{~L} \rightarrow$ $2 \mathrm{~L}$ ) had no significant impact on the sensitivity due to the strong and broad absorption of sevoflurane, which could hide additional species with weaker absorption. Concentrations for all the identified components in the 27 measured smoke samples (plus the two blanks H01a and H03a) are given in Table 5.

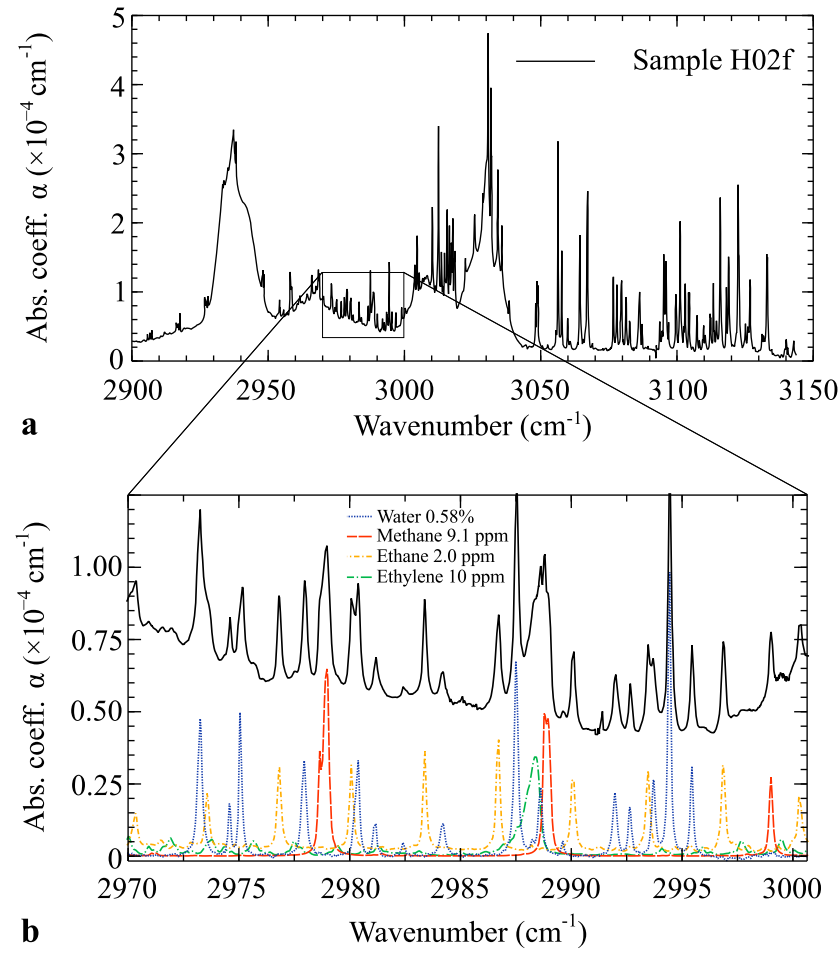

Fig. 8 (a) Typical absorption spectrum of a surgical smoke sample measured with the mid-infrared DFG spectrometer (pressure $=$ 950 mbar, temperature $=25^{\circ} \mathrm{C}$, path length $=35 \mathrm{~m}$ ). (b) Magnified view of the $2970-3000 \mathrm{~cm}^{-1}$ region, where absorption lines of water vapor, methane, ethane and ethylene are visible

With the NIR spectrometer, only carbon monoxide (CO) and hydrogen fluoride (HF) were targeted, although water vapor and methane could be measured as well. We hypothesized that hydrogen fluoride could be generated in an atmosphere containing sevoflurane vapor if sufficient energy 
Table 5 Chemical composition of the 29 samples measured with the MIR DFG spectrometer

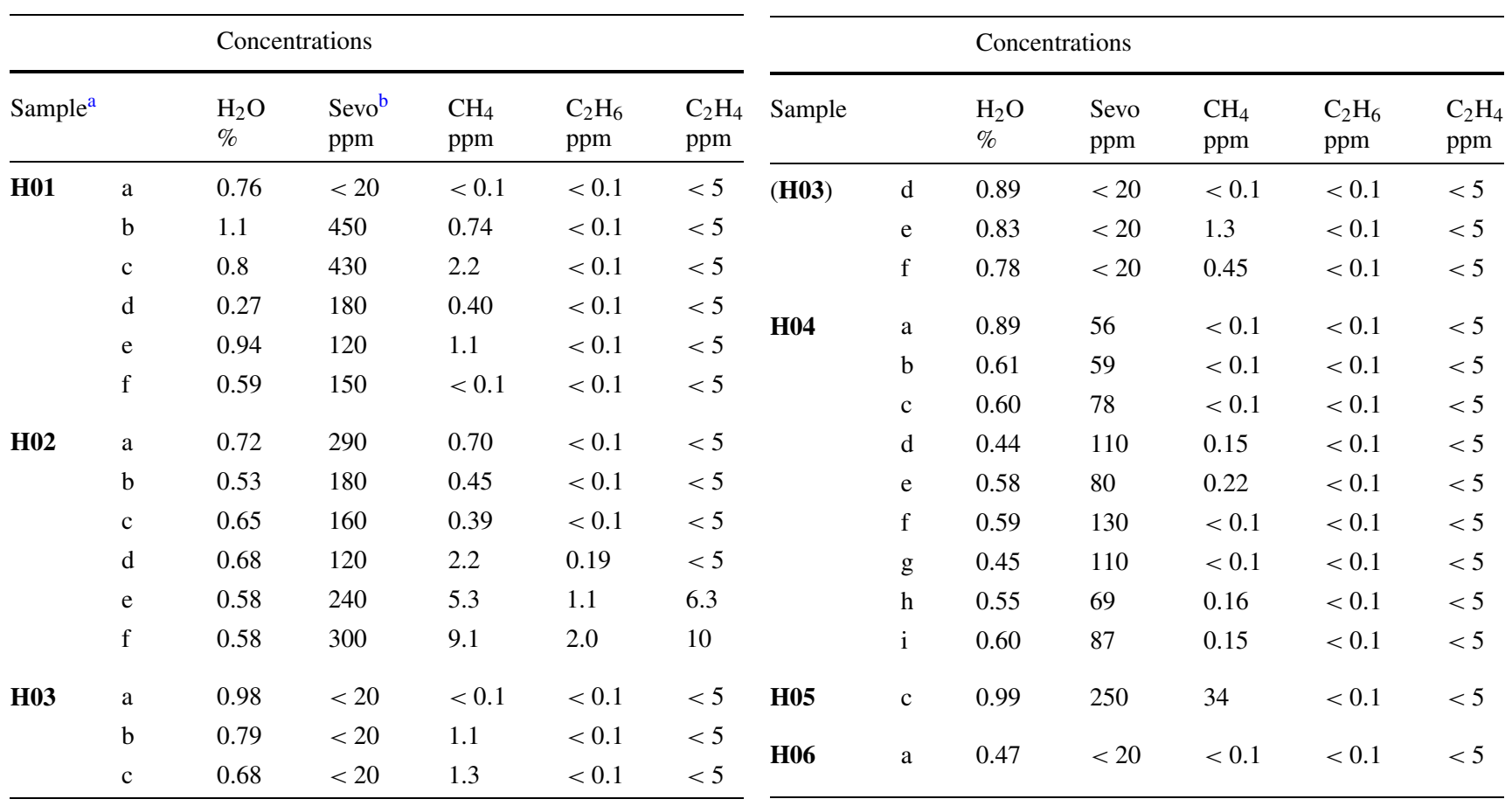

${ }^{\mathrm{a}}$ For a description of the samples, see Table 4

${ }^{\mathrm{b}}$ Sevoflurane $\mathrm{C}_{4} \mathrm{H}_{3} \mathrm{~F}_{7} \mathrm{O}$ (CAS no. 28523-86-6)

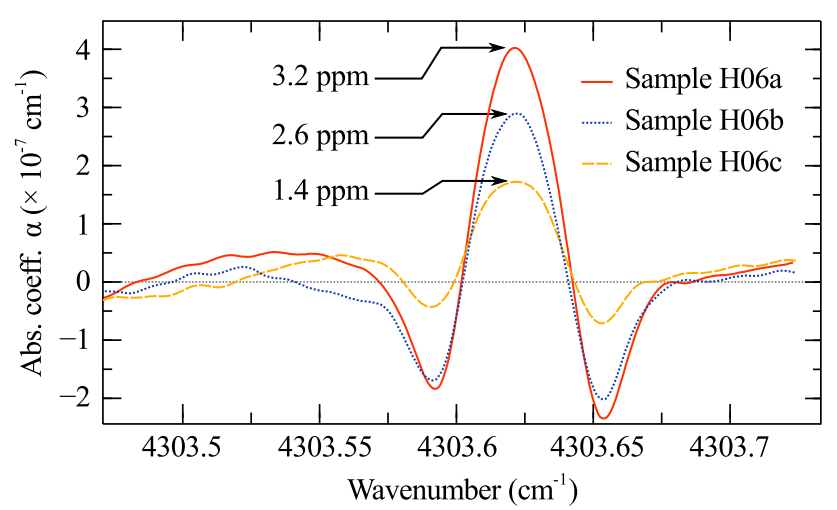

Fig. 9 Second-harmonic amplitude of the $\mathrm{CO}$ absorption line at $2323.6 \mathrm{~nm}$ measured in three surgical smoke samples

(heat) was provided. Indeed, an electrical discharge with a medical monopolar electroknife in a sevoflurane vapor atmosphere produced high levels (up to $130 \mathrm{ppb}$ ) of HF. However, in the smoke samples, HF remained always undetected (limit of detection (LOD): $110 \mathrm{ppt}$ ), but CO could be measured at concentrations up to $3.2 \mathrm{ppm}$ (LOD: $250 \mathrm{ppb}$ ). The $2 f$ signal amplitude (amplitude of the second harmonic) of the $\mathrm{CO}$ absorption line at $2323.6 \mathrm{~nm}$ is shown in Fig. 9. The measured concentrations of $\mathrm{HF}$ and $\mathrm{CO}$ are summarized in Table 6.
Table 6 Results for the six samples measured with the NIR spectrometer

\begin{tabular}{llll}
\hline Sample $^{\mathrm{a}}$ & $\begin{array}{l}\text { CO } \\
\mathrm{ppm}\end{array}$ & $\begin{array}{l}\mathrm{HF} \\
\mathrm{ppb}\end{array}$ \\
\hline H05 & $\mathrm{a}$ & 0.30 & $<0.11$ \\
& $\mathrm{~b}$ & $<0.25$ & $<0.11$ \\
& $\mathrm{c}$ & $<0.25$ & $<0.11$ \\
$\mathbf{H 0 6}$ & $\mathrm{a}$ & 3.2 & $<0.11$ \\
& $\mathrm{~b}$ & 2.6 & $<0.11$ \\
& $\mathrm{c}$ & 1.4 & $<0.11$ \\
\hline
\end{tabular}

${ }^{\mathrm{a}}$ For a description of the samples, see Table 4

For an overview of the MIR region from 5000 to $1000 \mathrm{~cm}^{-1}$, the spectrum of sample H01f (Table 4) was recorded with a FTIR spectrometer. The result is shown in Fig. 10. Water vapor and carbon dioxide saturate the absorption in several spectral regions: $1320-1910 \mathrm{~cm}^{-1}$ (water), 2240-2380 $\mathrm{cm}^{-1}$ (carbon dioxide) and 3530-3960 $\mathrm{cm}^{-1}$ (both). The absorption features in the range accessible with the MIR DFG spectrometer are visible in the FTIR spectrum, too. The nine broad absorption peaks between 1000 and $1400 \mathrm{~cm}^{-1}$ can be attributed to sevoflurane [55]. No additional species could be detected in the FTIR spectrum. 


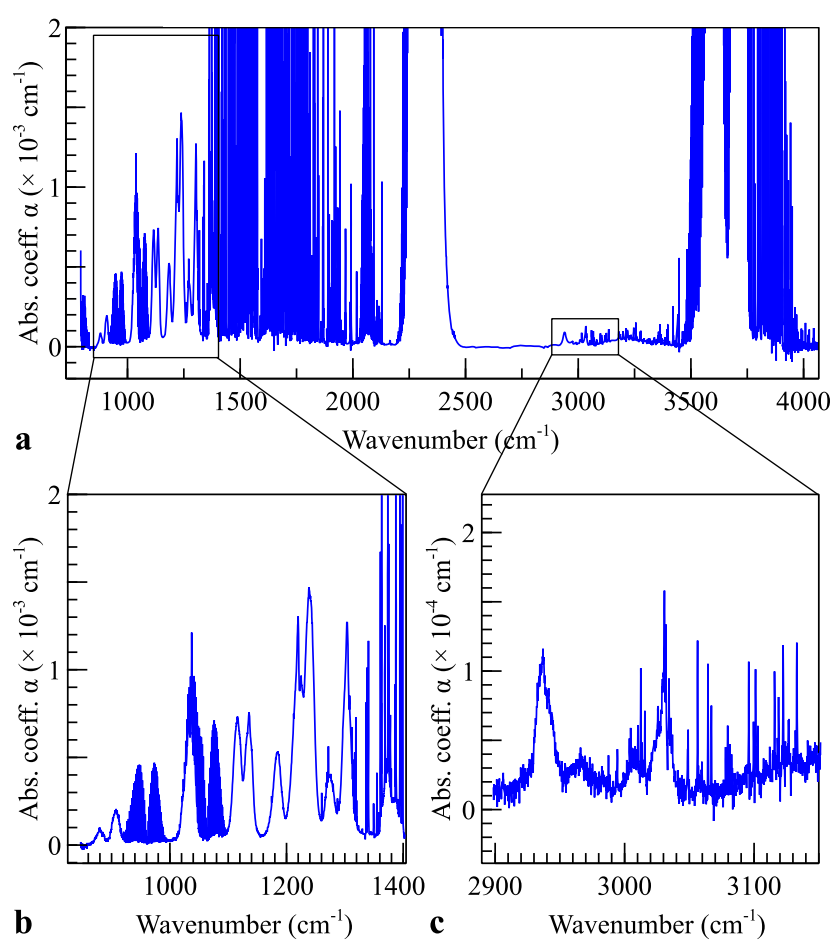

Fig. 10 (a) Spectrum of sample H01f measured with the FTIR spectrometer from 800 to $4000 \mathrm{~cm}^{-1}$. Water vapor and carbon dioxide saturate the absorption between 1400 and $2500 \mathrm{~cm}^{-1}$ and between 3500 and $4000 \mathrm{~cm}^{-1}$. (b) Magnification of the spectral region 900-1400 $\mathrm{cm}^{-1}$. The 10P, 10R, 9P and 9R branches of $\mathrm{CO}_{2}$ are visible, as well as several absorption bands due to sevoflurane. (c) Magnification of the spectral region $2900-3150 \mathrm{~cm}^{-1}$. This corresponds to the region measurable with the DFG spectrometer. The sevoflurane absorption peaks are visible (cf. Fig. 8)

\section{Discussion}

The spectra of surgical smoke samples measured with the MIR DFG spectrometer were similar in composition to smoke samples produced in the laboratory on animal tissue in an earlier study [56], where water vapor, methane, ethane and ethylene were the only detected compounds. Methane, ethane and ethylene are relatively harmless, with recommended exposure limits (REL) of $1 \%$ [57]. With concentrations in the low-ppm range (Table 5), they can be considered safe.

Concentrations of $\mathrm{CO}$ measured in the six surgical smoke samples ranged from below the limit of detection (LOD) of $250 \mathrm{ppb}$ up to $3.2 \mathrm{ppm}$ (Table 6). This value is well below the REL of $30 \mathrm{ppm}$ for CO [57]. Additionally, when $\mathrm{CO}$ is released from the abdominal cavity into the operation room (OR), a dilution occurs. It should be noted, however, that REL values apply to inhaled amounts: CO produced intraperitoneally is absorbed into the blood circulation of the patient directly, where it causes an increase of carboxyhemoglobin (HbCO). Esper and co-workers [58] detected an increase of $\mathrm{HbCO}$ in patients undergoing laparoscopic cholecystectomy with thermocautery equipment and linked it to a significant increase in intraperitoneal $\mathrm{CO}$ levels (from 4.7 to $326 \mathrm{ppm}$ ). In a more recent study, even higher levels of CO (>490 ppm) were detected during endoscopic urological resections [25]. The much lower CO concentrations found in the present study $(\leq 3.2 \mathrm{ppm})$ can be attributed to the lower operating temperature of the employed vessel sealing device and to the small amount of smoke produced. In the same work, the authors also detected toluene (5 ppb), styrene ( $2 \mathrm{ppb})$, xylene ( $2 \mathrm{ppb})$, benzene ( $5 \mathrm{ppb})$ and formaldehyde $(5.8 \mathrm{ppb})$. These concentrations are all below the REL and below the LOD of our MIR DFG spectrometer.

Despite the very low LOD of only $110 \mathrm{ppt}$, hydrogen fluoride was not detected in any of the six measured samples. Although, as laboratory experiments have shown, small quantities could be produced in an atmosphere containing sevoflurane vapor, hydrogen fluoride is corrosive and penetrates easily through porous substances. Hence, if only small amounts are produced, it is unlikely that they will reach the multipass cell or even the sample bag.

It is not certain how the anaesthetic sevoflurane reaches the abdominal cavity of the patient, but, since it is very volatile (vapor pressure: $263 \mathrm{mbar}$ at $25^{\circ} \mathrm{C}$ ), inhaled at high (few percent) concentration and then absorbed into the patient's bloodstream, a small amount could diffuse into the abdominal cavity. Due to its broad and relatively strong absorption features (Fig. 8a), the presence of sevoflurane interferes with the detection of other trace gases and reduces the usefulness of preconcentration techniques. Better sensitivities can be expected if sevoflurane could be removed selectively from the gas samples. However, the presence of a volatile anaesthetic in the abdominal cavity of the patient is of great interest per se, since long-term exposure to low levels of halogenated anaesthetics is thought to have undesirable effects [59-61], which is why the US National Institute for Occupational Safety and Health (NIOSH) recommends an exposure limit of 2 ppm (8-h time-weighted average) for all halogenated anaesthetics [62]. The release of smoke from the abdominal cavity of the patient into the OR, because of leakage or intentionally (e.g. to restore visibility), is therefore accompanied by the release of sevoflurane vapor. Hence, it is an additional source of waste anaesthetic gas (WAG) pollution [59, 60, 63-79]. Known sources of WAG pollution include leakage from the patient's mask, from endotracheal coupling, from loose tube fittings and from air exhaled by the patient in the recovery room. It is unknown to which extent anaesthetic gas escaping from the patient's pneumoperitoneum affects the exposure of OR personnel to WAG.

In view of the multitude of chemical compounds detected in previous studies (Table 1), it is somewhat surprising that only very few could be found here. On the one hand, the sensitivity of our MIR DFG spectrometer is not comparable with state-of-the-art GC-MS equipment, and the much 
better sensitivity of our NIR spectrometer comes at a price of only being able to detect a few substances. On the other hand, for the purpose of assessing the risk linked to surgical smoke exposure, sub-ppm sensitivity is not strictly necessary, since the RELs for most compounds are in the ppm range. Notable exceptions are benzene and formaldehyde, which, given their toxicity and carcinogenity, have very low RELs. A few compounds with their RELs and LODs are given in Table 7. None of the listed substances was detected. Those listed in the upper part have a LOD which is lower than the REL, and can be considered harmless. For those in the lower part no such statement can be made: additional measurements with more sensitive equipment are needed.

\section{Conclusions}

The chemical composition of surgical smoke collected during minimally invasive surgery at the University Hospital Zurich has been studied with a mid-infrared differencefrequency-generation-based laser spectrometer (2817$3144 \mathrm{~cm}^{-1}$, Fig. 1), a near-infrared spectrometer with two distributed feedback laser diodes (for CO (2323.6 nm) and HF (2433.1 nm) detection, Fig. 4), and a Fouriertransform infrared (FTIR) spectrometer. The purpose of this study was to obtain quantitative data in order to establish the risk for operation room (OR) personnel and patients in relation to the exposure to surgical smoke. The spectroscopic measurements on the surgical smoke samples yielded the following composition: water vapor $(0.27-$ $1.1 \%)$, methane $(<0.1-9.1 \mathrm{ppm})$, ethane $(<0.1-2 \mathrm{ppm})$, ethylene $(<5-10 \mathrm{ppm})$, sevoflurane $(<20-450 \mathrm{ppm})$ and carbon monoxide $(<0.25-3.2 \mathrm{ppm})$ (Tables 5 and 6$)$. Except for the anaesthetic sevoflurane, the concentrations of all compounds are below the recommended exposure limits (RELs [57]). Due to the presence of sevoflurane in the patient's pneumoperitoneum, gas released into the OR is a cause of waste anaesthetic gas (WAG) pollution. The limited number of detected compounds can be attributed to the sensitivity of the employed spectrometers, which for most substances lies in the ppm range. Although some very toxic compounds need to be detected at sub-ppm concentrations, most have RELs in the ppm range (Table 7), so that sub-ppm sensitivity is not strictly required. For those compounds that do require sub-ppm LODs (e.g. benzene, formaldehyde), more research with more sensitive instruments is needed. The composition of the samples remained stable over several weeks after the first measurement. However, nothing can be said about the stability during the first few hours after sampling and before the first measurement. In conclusion, the only substance of relevance from a health and safety perspective found in the present study is sevoflurane. Notice, however, that we restricted our investigation to the gas phase and ignored the solid (aerosol) phase.
Table 7 Limits of detection (LOD, with the MIR DFG spectrometer) and recommended exposure limits (REL) for a few selected compounds. Upper part: compounds which could be detected at concentrations below the REL (LOD $<$ REL). Lower part: compounds which could not be detected at or below the REL (LOD > REL)

\begin{tabular}{lcc}
\hline Substance & $\begin{array}{c}\text { LOD } \\
\text { ppm }\end{array}$ & $\begin{array}{c}\text { REL } \\
\text { ppm }\end{array}$ \\
\hline Toluene & 8.8 & 50 \\
Styrene & 11 & 20 \\
Acetone & 14 & 150 \\
p-Xylene & 6.5 & 100 \\
m-Xylene & 7.7 & 100 \\
o-Xylene & 7.6 & 100 \\
Ammonia & 750 & 20 \\
Formaldehyde & 0.78 & 0.3 \\
Benzene & 8.7 & 0.5 \\
Acrylonitrile & 150 & 2 \\
\hline
\end{tabular}

Acknowledgements We thank D. Hahnloser, University Hospital Zurich, for the fruitful collaboration. We also thank Nanoplus $\mathrm{GmbH}$ for providing the laser diode for the carbon monoxide measurements. Financial support from the Swiss National Science Foundation (SNSF) and ETH Zurich is gratefully acknowledged.

\section{References}

1. W. Barrett, S. Garber, Surg. Endosc. 17, 979 (2003)

2. W. Francke, O. Fleck, D.-L. Mihalache, W. Wöllmer, Proc. SPIE 2323, 423 (1995)

3. C. Hensman, D. Baty, R. Willis, A. Cuschieri, Surg. Endosc. 12, 1017 (1998)

4. K. Desinger, W. Wäsche, H. Albrecht, Proc. SPIE 2624, 234 (1996)

5. W. Wäsche, H. Albrecht, G.J. Mueller, Proc. SPIE 2323, 393 (1995)

6. M. Spleiss, L.W. Weber, Proc. SPIE 2923, 168 (1996)

7. M. Spleiss, L. Weber, T. Meier, B. Treffler, Proc. SPIE 2323, 409 (1995)

8. H. Albrecht, R. Hagemann, W. Wäsche, G. Wagner, G.J. Mueller, Proc. SPIE 2077, 310 (1994)

9. L.W. Weber, M. Spleiss, Proc. SPIE 2323, 464 (1995)

10. H. Albrecht, W. Wäsche, G.J. Mueller, Proc. SPIE 2323, 455 (1995)

11. W. Wäsche, H. Albrecht, Proc. SPIE 2624, 270 (1996)

12. H.-J. Weigmann, J. Lademann, J. Liebetruth, Proc. SPIE 2077, 264 (1994)

13. H.-J. Weigmann, J. Lademann, H. Meffert, W. Sterry, Proc. SPIE 2923, 164 (1996)

14. P. Sagar, A. Meagher, S. Sobczak, B. Wolff, Br. J. Surg. 83, 1792 (1996)

15. J.M. Rey, D. Schramm, D. Hahnloser, D. Marinov, M.W. Sigrist, Meas. Sci. Technol. 19, 075602 (2008)

16. M. Baggish, B. Poiesz, D. Joret, P. Williamson, A. Rebai, Lasers Surg. Med. 11, 197 (1991)

17. P. Hallmo, O. Naess, Em. Arch. Otorhinolaryngol. 248, 425 (1991)

18. L. Calero, T. Brusis, Laryngo-Rhino-Otologie 82, 790 (2003) 
19. J.M. Garden, M.K. O’Banion, A.D. Bakus, C. Olson, Arch. Dermatol. 138, 1303 (2002)

20. B. Ziegler, C. Thomas, T. Meier, R. Muller, T. Fliedner, L. Weber, Lasers Surg. Med. 22, 37 (1998)

21. D. Jewett, P. Heinsohn, C. Bennett, A. Rosen, C. Neuilly, Am. Ind. Hyg. Assoc. J. 53, 228 (1992)

22. P. Heinsohn, D. Jewett, Am. Ind. Hyg. Assoc. J. 54, 446 (1993)

23. K.J. Weld, S. Dryer, C.D. Ames, K. Cho, C. Hogan, M. Lee, P. Biswas, J. Landman, J. Endourol. 21, 347 (2007)

24. A.R. Moot, K.M. Ledingham, P.F. Wilson, S.T. Senthilmohan, D.R. Lewis, J. Roake, R. Allardyce, ANZ J. Surg. 77, 20 (2007)

25. R. Weston, R.N. Stephenson, P.W. Kutarski, N.J. Parr, Urology 74, $1152(2009)$

26. O.S. Al Sahaf, I. Vega-Carrascal, F.O. Cunningham, J.P. McGrath, F.J. Bloomfield, Ir. J. Med. Sci. 176, 229 (2007)

27. Y.J. Chung, S.K. Lee, S.H. Han, C. Zhao, M.K. Kim, S.C. Park, J.K. Park, Int. J. Urol. 17, 944 (2010)

28. D. Galbraith, S.A. Gross, D. Paustenbach, Crit. Rev. Toxicol. 40, 1 (2010)

29. L. Lehman-McKeeman, Toxicol. Sci. 116, 361 (2010)

30. D.S. Bomse, A.C. Stanton, J.A. Silver, Appl. Opt. 31, 718 (1992)

31. M. Seiter, M.W. Sigrist, Appl. Opt. 38, 4691 (1999)

32. C. Dyroff, D. Fuetterer, A. Zahn, Appl. Phys. B 98, 537 (2010)

33. L. Ciaffoni, R. Grilli, G. Hancock, A.J. Orr-Ewing, R. Peverall, G.A.D. Ritchie, Appl. Phys. B 94, 517 (2009)

34. A. Elia, C.D. Franco, P.M. Lugara, G. Scamarcio, Sensors 6, 1411 (2006)

35. D. Romanini, M. Chenevier, S. Kassi, M. Schmidt, C. Valant, M. Ramonet, J. Lopez, H. Jost, Appl. Phys. B 83, 659 (2006)

36. S. Schilt, A.A. Kosterev, F.K. Tittel, Appl. Phys. B 95, 813 (2009)

37. C. Wang, P. Sahay, Sensors 9, 8230 (2009)

38. A. Kosterev, G. Wysocki, Y. Bakhirkin, S. So, R. Lewicki, M. Fraser, F. Tittel, R. Curl, Appl. Phys. B 90, 165 (2008)

39. F.K. Tittel, A.A. Kosterev, Appl. Phys. B 85, 171 (2006)

40. C. Fischer, M.W. Sigrist, Mid-IR difference frequency generation, in Solid-State Mid-infrared Laser Sources. Top. Appl. Phys., vol. 89 (Springer, Berlin, 2003), pp. 97-140

41. M. Gianella, M.W. Sigrist, Appl. Opt. 50, A11 (2011)

42. M. Gianella, Analysis of surgical smoke by infrared laser spectroscopy, Ph.D. thesis, ETH Zurich (2011)

43. R. Bartlome, M. Baer, M.W. Sigrist, Rev. Sci. Instrum. 78, 013110 (2007)

44. P. Werle, R. Mücke, F. Slemr, Appl. Phys. B 57, 131 (1993)

45. J.A. Barnes, A.R. Chi, L.S. Cutler, D.J. Healey, D.B. Leeson, T.E. McGunigal, J.A. Mullen, W.L. Smith, R.L. Sydnor, R.F.C. Vessot, G.M.R. Winkler, IEEE Trans. Instrum. Meas. IM-20, 105 (1971)

46. J. Silver, Appl. Opt. 31, 707 (1992)

47. C. Tang, J. Telle, J. Appl. Phys. 45, 4503 (1974)

48. E. Moses, C. Tang, Opt. Lett. 1, 115 (1977)

49. D.E. Jennings, Appl. Opt. 19, 2695 (1980)

50. H.A. Spaink, T.T. Lub, H.C. Smit, Anal. Chim. Acta 241, 83 (1990)

51. L. Rothman, I. Gordon, A. Barbe, D. Benner, P. Bernath, M. Birk, V. Boudon, L. Brown, A. Campargue, J.-P. Champion, K. Chance, L. Coudert, V. Dana, V. Devi, S. Fally, J.-M. Flaud, R. Gamache, A. Goldman, D. Jacquemart, I. Kleiner, N. Lacome, W. Lafferty, J.-Y. Mandin, S. Massie, S. Mikhailenko, C. Miller, N. MoazzenAhmadi, O. Naumenko, A. Nikitin, J. Orphal, V. Perevalov, A. Perrin, A. Predoi-Cross, C. Rinsland, M. Rotger, M. Simeckova, M. Smith, K. Sung, S. Tashkun, J. Tennyson, R. Toth, A. Vandaele, J.V. Auwera, J. Quant. Spectrosc. Radiat. Transf. 110, 533 (2009)
52. M. Gianella, M.W. Sigrist, Appl. Spectrosc. 63, 338 (2009)

53. S.W. Sharpe, T.J. Johnson, R.L. Sams, P.M. Chu, G.C. Rhoderick, P.A. Johnson, Appl. Spectrosc. 58, 1452 (2004)

54. T. Katoh, K. Ikeda, Anesthesiology 66, 301 (1987)

55. A. Brown, C. Canosamas, A. Par, J. Pierce, R. Wayne, Nature 341, 635 (1989)

56. M. Gianella, M.W. Sigrist, Sensors 10, 2694 (2010)

57. SUVA, Grenzwerte am Arbeitsplatz (SUVA, Lucerne, 2009)

58. E. Esper, T.E. Russell, B. Coy, B.E. Duke, M.H. Max, J.A. Coil, Surg. Endosc. 4, 333 (1994)

59. C. Byhahn, H.J. Wilke, K. Westphal, CNS Drugs 15, 197 (2001)

60. K.H. Hoerauf, T. Wallner, O. Akça, R. Taslimi, D.I. Sessler, Anesth. Analg. 88, 925 (1999)

61. M. Imbriani, P. Zadra, S. Negri, A. Alessio, L. Maestri, S. Ghittori, Med. Lav. 92, 173 (2001)

62. NIOSH, Criteria for a Recommended Standard: Occupational Exposure to Waste Anesthetic Gases and Vapors (National Institute for Occupational Safety and Health, Washington, 1977) pp. $77-140$

63. A. Accorsi, A. Barbieri, G.B. Raffi, F.S. Violante, Int. Arch. Occup. Environ. Health 74, 541 (2001)

64. A. Accorsi, S. Valenti, A. Barbieri, G.B. Raffi, F.S. Violante, Int. Arch. Occup. Environ. Health 76, 129 (2003)

65. C. Byhahn, K. Heller, V. Lischke, K. Westphal, World J. Surg. 25, 1109 (2001)

66. A. Gentili, A. Accorsi, A. Pigna, V. Bachiocco, I. Domenichini, S. Baroncini, F.S. Violante, Eur. J. Anaesthesiol. 21, 638 (2004)

67. B. Gustorff, N. Lorenzl, L. Aram, C.G. Krenn, B.P. Jobst, K.H. Hoerauf, Anesth. Analg. 94, 1244 (2002)

68. J.E. Hall, K.A. Henderson, T.A. Oldham, S. Pugh, M. Harmer, Br. J. Anaesth. 79, 342 (1997)

69. H. Heijbel, R. Bjurstöm, J.G. Jakobsson, Acta Anaesthesiol. Scand. 54, 1117 (2010)

70. J. Hobbhahn, K. Hoerauf, G. Wiesner, K. Schrögendorfer, K. Taeger, Acta Anaesthesiol. Scand. 42, 864 (1998)

71. J. Hobbhahn, G. Wiesner, K. Taeger, Anaesthesist 47 Suppl 1, S77 (1998)

72. K. Hoerauf, W. Funk, M. Harth, J. Hobbhahn, Anaesthesia 52, 215 (1997)

73. K.H. Hoerauf, C. Koller, K. Taeger, J. Hobbhahn, Int. Arch. Occup. Environ. Health 69, 134 (1997)

74. K. Hoerauf, T. Hartmann, A. Zavrski, S. Adel, H. Burger, H. Koinig, M. Zimpfer, Int. Arch. Occup. Environ. Health 72, 174 (1999)

75. K.H. Hoerauf, T. Hartmann, S. Acimovic, A. Kopp, G. Wiesner, B. Gustorff, H. Jellinek, P. Krafft, Br. J. Anaesth. 86, 124 (2001)

76. N. Raj, K.A. Henderson, J.E. Hall, I.M. Aguilera, M. Harmer, A. Hutchings, B. Williams, Anaesthesia 58, 630 (2003)

77. H. Rasmussen, S. Thorud, J. Am. Assoc. Lab. Anim. Sci. 46, 64 (2007)

78. G. Summer, P. Lirk, K. Hoerauf, U. Riccabona, F. Bodrogi, H. Raifer, M. Deibl, J. Rieder, W. Schobersberger, Anesth. Analg. 97, 1070 (2003)

79. B. Tankó, C. Molnár, T. Budi, C. Peto, L. Novák, B. Fülesdi, Anesth. Analg. 109, 1187 (2009)

80. R. Hollmann, C. Hort, E. Kammer, M. Nägele, M.W. Sigrist, C. Meuli-Simmen, Plast. Reconstr. Surg. 114, 458 (2004)

81. J. Wu, D. Luttmann, T. Meininger, N. Soper, Surg. Endosc. 11, 1075 (1997) 